\title{
The Three Gorges Dam Project-Religious Practices and Heritage Conservation
}

A study of cultural remains and local popular religion in the xian of Yunyang (municipality of Chongqing)

\section{Katiana Le Mentec}

\section{(2) OpenEdition}

\section{Journals}

Electronic version

URL: http://journals.openedition.org/chinaperspectives/626

DOI: $10.4000 /$ chinaperspectives.626

ISSN: 1996-4617

\section{Publisher}

Centre d'étude français sur la Chine contemporaine

\section{Printed version}

Date of publication: 1 June 2006

ISSN: 2070-3449

\section{Electronic reference}

Katiana Le Mentec, «The Three Gorges Dam Project-Religious Practices and Heritage

Conservation », China Perspectives [Online], 65 | may - june 2006, Online since 21 December 2006, connection on 28 October 2019. URL : http://journals.openedition.org/chinaperspectives/626 ; DOI : 10.4000/chinaperspectives.626

This text was automatically generated on 28 October 2019

(c) All rights reserved 


\title{
The Three Gorges Dam Project- Religious Practices and Heritage Conservation
}

\author{
A study of cultural remains and local popular religion in the xian of \\ Yunyang (municipality of Chongqing)
}

\author{
Katiana Le Mentec
}

\section{EDITOR'S NOTE}

Translated from the French original by Peter Brown

I would like to thank Brigitte Baptandier whose enlightened remarks have been a considerable contribution to this article.

1 The subject of much media attention, the new dam at Yichang in the western part of Hubei province is of great and varied consequence for upstream areas, particularly the Three Gorges region. The retention of water at the point of this massive structure is having a huge impact on the river basin of the Changjiang. The rise in the water level upstream from the dam, which by 2007 will reach a height of one hundred and seventyfive metres, is slowly but surely causing the wholesale flooding of agricultural lands, cities, townships, factories and archaeological and historical sites, as well as the resettlement of between one million three hundred thousand and two million people ${ }^{1}$. The dam was one of the first projects in China to have funds allocated for heritage protection and conservation. Yet the very cultural richness of the region means this has been a matter of some controversy in recent years. Indeed, whilst the government may well be proud of giving a billion yuan for the protection of cultural remains, this sum will barely enable $1 \%$ of sites to be saved, even assuming that the promised money is provided in full. Under the auspices of this heritage conservation, archaeological and historical sites are being removed from their original location, dismantled and relocated in specially adapted areas devised according to government plans. 
Accordingly, museums, as well as new artificial sites comprising "cultural parks", are being constructed, which will bring together buildings and relics-such as statues or stone engravings-transferred for the purpose.

2 I have been investigating the cultural and symbolic repercussions of the trauma produced in the Three Gorges region by the disappearance of the land of the forebears, the topographical modification of sites and the ensuing forced migration. My research has, in particular, involved moves aimed at recomposing tradition and constructing identity, especially the current reinventions and reinvestments of the past on the part of both the government and the population at large. In this article I tackle the thorny issue of what the local government defines as "local heritage", notably cultural, historical and religious relics and the worship of deities. In the very particular economic (both past and present), geographical and historical context of the region, I try to bring out the underlying implications of these fundamental elements of the community as well as the local policies dealing with them. I am not seeking to give an overall account here, but to offer some partial insight into one particular place, the district of Yunyang, located in the north-eastern part of the municipality of Chongqing, about two hundred kilometres upstream from the dam. Out of the whole area it is the place that has been the worst affected by the rising waters and consequently the one with the highest number of resettlements. Having conducted fieldwork there on several occasions between May and December 2004 and January and February 2006, my aim in this article is to raise a certain number of anthropological questions relating to the momentous changes that the region is undergoing.

Local heritage put to work for tourism

Considering the importance of the tourist industry in the economy of a country or region today, one can readily understand the interest of governments to invest in and promote cultural heritage, which, like the landscape, constitutes one of the most important attractions for travellers. In fact, the economic interest represented by tourism can even be said to be vital in this far-flung and mainly rural mountainous area, which, having lived in virtually total isolation until very recently, is struggling to develop. The Three Gorges region, highly prized by tourists, famous as it is for its ancient and contemporary history as well as for its magnificent views, is facing a significant challenge. Following the rise in the water level, it will have to somehow encourage tourism despite the loss of many sunken relics and the inevitable loss of charm due to the transformation of the landscape. In Yunyang, the local culture, along with the historical and religious sites, constitute significant assets for tourism. After a government selection process, these are now enjoying protective measures-within the constraints of the budget-and new "local heritage" tourist sites are being promoted. In this first part, I present several such sites that are the subject of tourist investment, in order to understand how they and other state initiatives involve at their core many complex and important issues. 


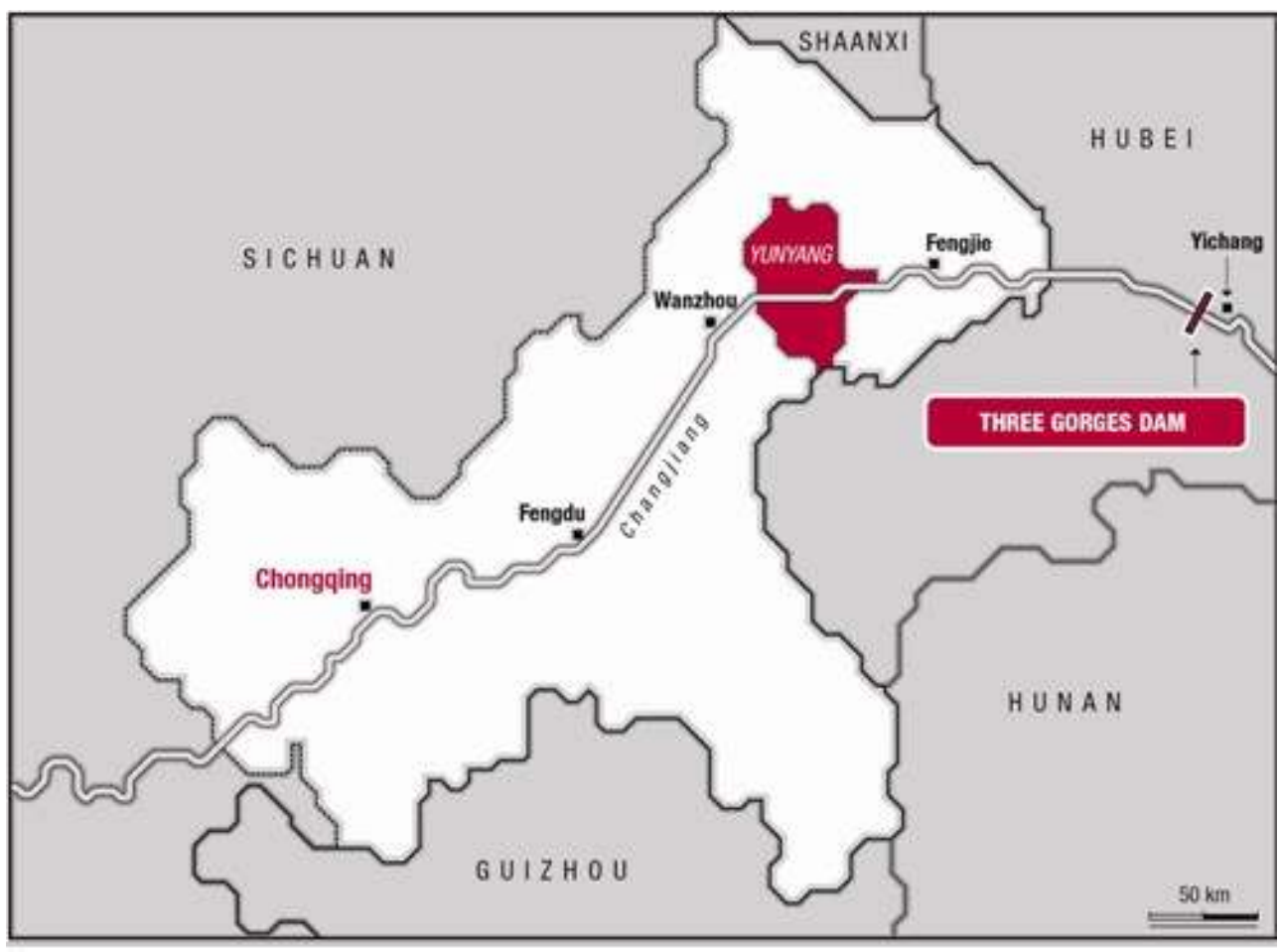

Zhangwang Pusa ${ }^{2}$, whose cult is not widespread in China, represents a fine opportunity for the development of local tourism. A national historical character, he is known even beyond the borders. I am talking about General Zhang Fei, a hero from the age of the Three Kingdoms (220-280), who was assassinated in 221 by two of his officers ${ }^{3}$. In Yunyang, the temple dedicated to him lies opposite the district's capital, on the southern banks of the Changjiang. "According to attested accounts, this was built more than 1,700 years ago [...]. Current research on the writings traces his story back to the time of the Northern Song dynasty (1119-1125)"

One legend, encountered time and again in the field, reveals the mythological origin of this building. It tells of the adventure of Zhang Fei's killers who, after murdering him, wanted to seek refuge in the enemy kingdom of $\mathrm{Wu}$ in the hope of gaining asylum there by delivering his head. On the river, at the level of Yunyang district ${ }^{5}$, they are said to have heard about the peace concluded in the meantime between the lands of shu and $\mathrm{Wu}$. Losing hope of gaining the favours of the king of $\mathrm{Wu}$, they then supposedly threw the skull of the famous general into the river. According to the legend, the spot where the head was came to a fisherman in a dream, thus he was able to find it. While the old man was doing this, Zhang Fei appeared before him and asked him not to let his head drift down the river as far as enemy territory, but to bury it in the land of Shu, at Yunyang, on the hill of the Flying Phoenix opposite the river. This temple, much more than a simple commemorative construction, today represents only the visible part of the cult of Zhang Fei, which is still very much alive. At Yunyang, the memory of the inhabitants as well as the Annals of the district report the presence in the past of nearly twenty temples honouring him, most of which are now destroyed or under water. In the countryside, however, I also visited several other places of worship housing his statue. In the temple facing the river, for example, General Zhang, regarded as the 
protective territorial deity of Yunyang and its inhabitants, has, according to local sources, also been venerated as the god of boatmen since the beginning of the Qing dynasty. The structure has been successively enriched over the centuries by the addition of numerous buildings, and it is known for the collection of art works that it contains, particularly its engravings on wood and stone. This monument today forms part of the package of sites visited by cruises organised along the Changjiang. Officially protected by the state since 1997, it was declared a national trust site on June $25^{\text {th }} 2001$.

Named after a nationally famous figure, with an ancient and legendary foundation and an admirable art collection, the temple of Zhang Fei is an obvious example of a culturally rich site and occupies a special place in local development policy. Two years ago, it was still standing opposite the capital of Yunyang, and the rising waters would have partially covered it had it not been relocated. In the heritage protection programme of the Three Gorges region it was the project that clearly called for the lion's share of funding. As a result, it was completely dismantled before being reconstructed piece by piece thirty kilometres upstream, opposite the new city of Yunyang (Xin Yunyang). This initiative enabled the temple to take advantage of unprecedented public attention. The building that had survived the Cultural Revolution was put under local government control. It had already been partially restored, a process accelerated with relocation.

\section{2- Zhang Fei temples in Yunyang}

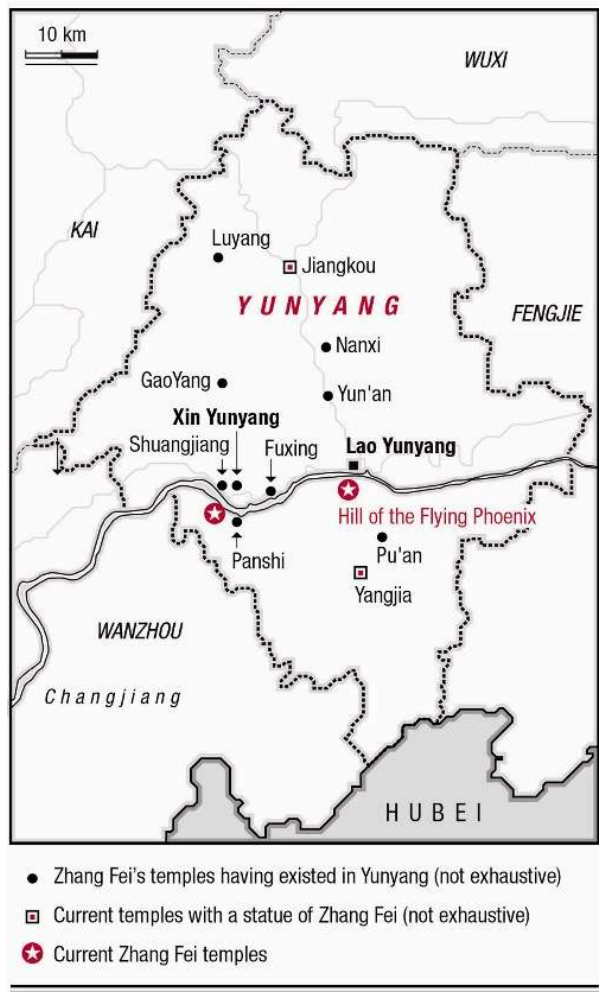

7 This also involved a certain number of modifications. It took on some additional rooms that were opened after the transfer ${ }^{6}$. These have been set up since the relocation by the small community of Buddhists present, with the agreement of the authorities. They offer services to the faithful and, according to the temple's administrators, are there to "respond to the needs of some visitors to the temple". The collection of art works at the 
site has been enriched by features that have been restored or replaced, like for example the new bronze statues of Zhang Fei, created in 2002 by a teacher from the Art Institute of Sichuan. The site's administrators have also provided the temple with more modern equipment, such as an interactive computer and a television showing a programme that presents a brief overview of the General's history. There is also, in front of the entrance door, a photographer's counter equipped with a digital camera. The temple seems to have been gradually transformed into a national, or even international, tourist site, as it is ready to receive foreigners thanks to the presence, since the relocation, of an English-speaking guide. It is not as a place of worship that it appears in the published documents, but solely as a "historic relic". The temple's recognition as a nationally listed monument clearly indicates its official new status.

The temple of Zhang Fei is the most famous one in Yunyang, but it is not the only monument to have been removed from its original site. All over the district, many cultural and historical remains have been retrieved by the authorities. A new "cultural park", still under construction, is home to part of them'. Following the example of many holy places in China, it is located atop a hill, the very one where Xin Yunyang was established. It has been set up at the foot of the old fortified city of Panshi, currently being restored and already open to tourists. Some relocated features are also to be found sometimes as part of urban development projects taking shape in the new capital, like for example on the walk along the river.

These new tourist spots are not the only initiatives of the local government, which has published a book of old and recent photos of the district as well as a pack of collector's stamps featuring the famous bridges and scenery of the gorges and episodes from the time of the Three Kingdoms. In Xin Yunyang, the historical and religious remains are turning out to be fundamental. The regional economic crisis has been made worse by job losses following the submerging of agricultural lands, factories and businesses. It is all about attracting visitors, but also investors, as the economy has to be reconstructed and stimulated. Tourism and urban projects such as the new shopping mall are designed to encourage tourists to stay on in Yunyang and, indeed, to spend a few nights in the new luxury hotels there. However, what interests me much more than the study of tourist development are the various ways in which places of worship, cultural relics and local deities are being reappropriated as part of a complex political programme. For the local government, the flooding of land constitutes a wonderful opportunity to restore, but also reappropriate, sites and objects of local history that thereby become the focus of significant political and ideological interest.

Reconfiguring places of worship and cultural relics

In the Three Gorges, only certain elements regarded as "cultural heritage" have benefited from conservation funds. Others, deliberately kept out of the relocation exercise, have no doubt been deemed to be either too recent, too "modest" or involving "superstitious" practices. Among these are some temples off the beaten tourist track that are even more rustic, like the smaller ones dedicated to Zhang Fei or containing his statue. They were, moreover, often looked down upon by the urban residents I interviewed, who characterised them as "inauthentic" or "culturally worthless". Some are doubtless secondary places of worship that people would like to see done away with in favour of the only "real monument" commemorating Zhang Fei, which is to be found facing the district's capital. As most of the places were still under construction during my last stay in Yunyang, I am not at present in a position to offer any detailed analysis 
of the various changes that have occurred there or of their many consequences. Accordingly, I will keep discussion here in the main to the case of Zhang Fei, his worship and his temple, commenting in the process on the important changes that I have been able to observe.

The temple's surroundings were disturbed at the time of its relocation. According to legend, the hill of the Flying Phoenix chosen by Zhang Fei plays an important role in the district by virtue of its luxurious vegetation and especially its very favourable geomancy. The transfer of the whole set of constructions involved the loss of this propitious fengshui in which the trees and the water were symbols of life. In its new location, it no longer benefits from the presence of the forest of cypress trees or the wonderful spring. Access to the site, which had always been primarily by boat, has also been modified. The construction of a giant bridge linking the southern and northern shores means that the temple can now be reached by road. For a god of boatmen, this is no neutral transformation.

Other changes concerning the reorganisation of the site have been put in place by the government. Inside the building, some features have been done away with altogether, while others have been added. The architectural whole and its garden are today surrounded by a stone wall. Outside the enclosure a new space was created for the worshippers who cannot afford the entry ticket and hence who are unable to place their offerings in the temple, access to which now requires payment. Furthermore, the fact that it is no longer permissible to put incense at the feet of Zhang Fei's statue has meant a significant change for the faithful, as this is a fundamental rite in the worship of a deity. Nevertheless, in the main room, Zhang Fei's head, symbolised by a wooden sculpture, continues to be the subject of ritual, and it is anointed in an oil offered to it for the purpose $e^{10}$. The presence of the jar of oil containing the mortal remains of the hero in the room of the god is fundamental, reminding everyone of the temple's foundation and legitimising worship, at the same time as enabling the god's effectiveness to continue.

The rituals of the traditional feast day celebrating Zhang Fei's birthday on the twentyeighth day of the eighth month of the lunar calendar have gradually been banned. The government now wishes to organise a certain number of activities to take place all through the week. This day, which gets a great many worshippers involved, plays an important role in the cohesion of the whole community. The new form it will take and its reception by the faithful will be particularly interesting to observe.

In Yunyang, the relocated buildings and relics are being managed for the time being by the state. This is an opportunity for the local government to get on with some changes to the sites and to the environment in which they are presented to the public. This process is not new in China where the state has always been concerned with regulating and controlling religious practices, and more especially the cults, which are regarded as a political tool and also a potential rival political power. The rising waters are enabling the local government to define what is officially authentic-that is historicaland what is not. It is the opportunity for it to sanction what is judged as being pure "superstitious belief", by excluding any of its manifestations that fall outside the boundaries of what it regards as cultural heritage. The authorities are not so much seeking to eradicate religious practices as to adapt them to make use of their social function. Zhang Fei, a hero and public servant who became a deity, a symbol of loyalty and courage, an emblem of national and local identity, fits perfectly well into the 
political propaganda of the state. The image of him in tales and novels is not always praiseworthy, though. Indeed, he is often characterised as fierce, brutal and without any refinement. But be that as it may, in Yunyang he is a glorious historical figure, endowed even with a poet's talents. For example, a stele inside the temple, bearing an inscription that he is supposed to have written himself, is testament to his assumed skill in calligraphy ${ }^{11}$. What is being promoted here in fact is not just any local god or popular place of worship, but, rather, a regional and national hero. This is one way of renewing religious practice to bring it more into line with the modern image that the government would like to give. The temple of Zhang Fei, classified national heritage remains and relocated stone by stone like a national historical vestige, yet without many of the foundational features of its worship, is presented more as a museum than as a religious centre. In Yunyang, the dam has allowed for an expansion of the process of converting holy places into historical and tourist sites that had already begun before the current upheaval.

Worship of the god Zhang Fei continues to exist side by side with this process. It remains lively and is practised by all the city's residents, whatever their age, be they from the country or the city, and whether they are civil servants, peasant farmers or workers (Zhang Fei's birthday celebrations in 2005 saw the active involvement of nearly ten thousand people according to the government, and more than five thousand tickets are said to have been sold). The temple is just as much a focus of interest for the elite as it is for followers from a more modest background. Everyone takes part in their own way and in line with their interests, which may vary over time in restoring, maintaining and enhancing the reputation of the site and guaranteeing the fame of the figure or deity ${ }^{12}$.

The people's disappointment with this relocated temple-which "no longer really looks like a temple", as I am regularly told-is manifest. They no longer enjoy themselves there so much, many things are lacking, but above all it is thought to be no longer as "effective", having lost, inter alia, its propitious surroundings, the offering of incense at the foot of the statue, and easy river access. In the countryside, there are stories that tell of Zhang Fei's displeasure and his refusal to be removed. So a small temple was rebuilt for him on his former site, tall enough to escape the next rise in the water level predicted for this summer. The origin of this new statue in stone has even enabled a new legend to spring up showing the god's effectiveness. Having just been erected, this temple offers the possibility for the development of certain activities that have been banned in the new temple (facing Xin Yunyang). Local mediums (called huopusa, living pusa) are thought to come and enact rituals there during the feasts of new year and the god's birthday ${ }^{13}$.

Broader ideological implications

The interest in controlling the historical and religious sites is not only commercial, but also political. Moreover, this is not the only benefit that the authorities derive from it. The remains and the holy places, which are regional sites of remembrance, also have their own symbolic codes that contribute to recreating a social dynamic within the traumatised region. In the context of the present upheavals, they are serving to consolidate and reorient community markers, and even to create new ones.

Identity upheaval 

Sichuan, which has enjoyed intermittent periods of political autonomy throughout its history ${ }^{14}$. In the region of Chongqing, the traces of Ba culture-omnipresent in Antiquity-are still perceptible and clearly promoted through the numerous archaeological sites of Yunyang. They enable the region's inhabitants to provide themselves with particularly positive markers of the past ${ }^{15}$. But it is also and especially the very particular topography of the place that has strengthened the unifying links among the population. Indeed, the districts in the north-east of the municipality of Chongqing lie in a mountainous region that virtually remained in complete isolation right throughout Chinese history, resulting in a culturally inward-looking approach. The region was too far removed from the political centres to fall really under imperial control. Furthermore, the decisions of the authorities, even the announcement of a new dynasty, took months to reach it. Only with the arrival of the communist government in power did it begin to open up to the outside world, thanks in particular to the works undertaken to improve the river traffic. The poor residents, eking out an existence under very difficult conditions, went through many trials and tribulations that have consolidated their sense of cohesion. experiencing a real trauma-not only geographical, but also economic and human-will find itself profoundly hurt by these upheavals ${ }^{16}$. The problem is real for those who leave, to be dispersed to the far-flung parts of the country ; they often find themselves displaced in other provinces that do not always welcome them with open arms. Stigmatised there, they rarely see any alternative other than to migrate to urban areas or come back to Yunyang without either land or place of abode. The harm is just as real for those who remain in the district and who more often than not have to settle in the reconstructed cities. The rise of the waters forces residents to leave their towns and their homes, at the same time as it sinks their original means of subsistence, the factories and the fields. They see the tombs of their ancestors disappear as well as their holy places, some of which are thousands of years old. They are bereft of their social networks and are forced to abandon their ancestral land, their village or their home territory to which they are attached but will doubtless never see again ${ }^{17}$.

In the midst of all this chaos, the people are worried about their future and that of their children. What place will historical remains and local religious practices have in this chaos? How will the government's initiatives enable, at least in part, courage and hope to be given back to the population?

The community's past

21 One of the priorities is to rally the residents around common identity markers and memories. Yunyang's population thus constitutes a privileged group for the new sites, as much as do tourists, albeit for a less economic ${ }^{18}$ and more ideological reason. Places under construction are going to bring together elements recalling the glorious history of the district, the past culture specific to the local population. The new "cultural park" represents in some way a mini version of the regional space, and the monuments erected there will take on meaning in this new context. Under this new arrangement, there will be a disruption to the testimony of history, as the vestiges saved from the waters will lose their former connection to place. Yet in its new historical, architectural and sociological environment the park will enable visitors from Yunyang to explore 
their homeland and find their memories, admittedly remodelled, that will stimulate their sense of belonging to the local community.

The worship of Zhang Fei also consolidates the foundations of the district, by allowing the inhabitants to rally round common values with a strong cohesive pull. The temple and the deity, both testaments to the past and marvellous crystallised examples of the local culture, constitute keys to these processes. We may wonder how the quintessential local culture is being expressed through this temple. First of all, the buildings making up the architectural whole recall local history of old $^{19}$; stellae commemorate both historical events and more recent ones, like the catastrophic flood of 1870 or the Second World War. Moreover, the structure houses a wonderful collection of historical remains of Ba culture and the Three Kingdoms period, as well as poems and engravings on stone and wood. Works recalling the great figures of the district are also on display. Similarly, the statues of regional or national divinities recall the religious history of the place. In the past, the temple of Zhang Fei was as important for the simple followers who came essentially to worship there as it was for the local elite which created or bought works to offer them to the deity and enrich the collection. It is through the trace of these manifold events, which marked local history over the course of dynasties that this temple seems to have stamped itself as a key element in the memory of the area.

23 However, the building is henceforth also integrated into the contemporary context. Firstly, objects it houses have been restored, and it has been equipped with modern facilities. In addition, the use made in the relocation process of hi-tech lasers for the recording of architectural details provided the opportunity for collaboration between the region and a Canadian firm. All these initiatives are enabling the temple's administrators to raise its profile and attract tourists. They also offer the opportunity to showcase the district's entry into modernity. By displaying the memories of local culture both past and present, the structure rallies the population around a project that can be a centrepiece for the future of the community.

During my research, the figure of Zhang Fei himself appeared to me as being profoundly tied up with the community of Yunyang. The people I interviewed frequently referred to the hero as loyal (yiqi), upright (gengzhi) or courageous (yonggan), qualities often attributed today to the local, even regional, temperament ${ }^{20}$. The similarity in character that pertains between the local population and the hero is sometimes clearly spelled out. Thus, a top ranking civil servant advised me recently that "the character of the people of Yunyang is relatively close to Zhang Fei's own". Indeed, the ancient and fundamental connection uniting deity and place comes through in many ways. It would seem, for example, that the cult of this deity crystallises elements regarded as stemming from Ba culture and the Sichuan and Chinese religious landscape, such as the theme of the control of water, or the figures of the snake and the tiger. It is also as protector of the residents of Yunyang that this god is mentioned in many accounts of miracles. Local legends tell for instance how Zhang Fei protected the territory from the British during the Opium War and from the Japanese during the Second World War. Finally, the ancestral and chthonian bond suggested by the legend of the inhumation of his head is strengthened by the putative existence of other relics of his body in the ground of the district. Indeed, a local rumour refers to the presence of the hero's hands and feet in villages to the north of Xin Yunyang ${ }^{21}$. The gods of the soil and the territory were a very fruitful force, regulating 
life and death and fundamentally maintaining community ties. The figure of Zhang Fei who is related to them would therefore seem to constitute an essential factor in stimulating once again the attachments of residents to this place.

Through all these changes, the temple and the religious practice both underlie and give impetus to the sense of community. Zhang Fei galvanises local pride and represents the region in modernity. In raising him and his temple into emblems of the district's cultural and historical richness, Yunyang and its people are also honoured. This enables the dispersed and badly affected residents to come together thanks to the former image of the god, who is now presented first and foremost as a historical figure, albeit one maintaining a power and a role similar to those of the popular deity.

Limiting the impact of the trauma

The government is also working to limit the impact of the relocation of the temple and the main town. For instance, it has published a new version of the legend of Zhang Fei in which no mention is made of the hill of the Flying Phoenix, thereby jettisoning its importance in the story. This new version was made public in 1992 in a little book presenting local history, which was distributed to all the schoolchildren of the district ${ }^{22}$. In addition, the local government claims that the city of Yunyang was originally situated near Shuangjiang, its current site. According to Communist Party historians, at the time of the Qin dynasty (221-206 B.C.) it was moved downstream near the mouth of the river in order to ensure better control of the transportation of salt. This history, stylised in the typically Chinese poetic form of couplets, contributes to relativising the shock of the town's relocation, and even to justifying it as a legitimate return to its original site.

old references altered, new ones created

The government is also striving to create new identity markers, for instance by establishing the "Three Gorges Day of Culture" and the Yunjiang park, in which are to be found the names of tens of thousands of displaced residents, as well as those of donors, engraved in stone during the construction or reconstruction of a temple. As a guarantor of the identity of displaced residents and, on that very account renewing their belonging to Yunyang, this new "holy place" bears traditional witness to their participation in the founding of the district. Formerly, it was the annual rituals of Zhang Fei's birthday-now banned in its traditional form-that enabled the local community to show its solidarity and sense of belonging. For its part, the culture day is organised and orchestrated under the auspices of the local government and falls under the umbrella of the recently established municipality of Chongqing. It is a little as if the authorities thought, with the new festivities of the temple, to take up again the former rites associated with the deity of the place and to introduce regional rites that are politically acceptable and liable to be integrated by all concerned. The government hopes thereby to retrieve the former ceremony's force of cohesion and its capacity to rally people, at the same time as proposing new celebrations. One significant fact is that one of them does not take place inside the temple at all, but right in the heart of the new city.

The flooding of lands and the reconstruction of towns and cities does not give rise to a simple restoration of the past. The reorganisation of the representations and emblems of the region constitutes an attempt at reinventing and manipulating previous references that are projected beyond the regional context, whilst still making use of a traditional language. This process allows an articulation of the past, the present and 
the future by recovering elements with a strong significance for the local community. The setting up of purpose-designed places and adequate ceremonies enables the partial reinterpretation of memories whose emotional potential has been revived. The relics and religious practices are thus called upon to play their part in a unifying project, and the government's initiatives point to the new direction for people to project themselves into a common future, one desired and conceived by the political authorities. The local government of Yunyang is seeking to forge a combination of images out of commonly shared elements, so as to politically remodel a coherent and moveable whole with the goal of reconstructing a strong and united district. These references constitute a mechanism of social control of which the government is, moreover, fully conscious.

The founding of the new city

29 Xin Yunyang ", "the new Yunyang", was built within the space of a few years and brings together, on the one site, the outskirts of the village of Shuangjiang and the submerged towns of Lao Yunyang and Yun'An ${ }^{24}$, something that would itself warrant a separate study. One can understand the local government's desire to stimulate a sense of community connection within a new urban entity where the residents have experienced major disruptions to their lives. Indeed, as I walked around the place I was easily able to discover the origin of residents, merely by reading the shop signs that still bore the name of their former location. In fact, depending on the neighbourhood, the residents variously call the place Shuangjiang, Yun'An or Yunyang. The metamorphosis of the capital, not only in its urban layout, but also its social fabric and markers of local memory, is causing the fraying of identities, and Xin Yunyang will have to give itself solid, new foundations if it is to obviate this problem.

The history being promoted by the government concerning the first "migration" from the capital at the time of the Qin dynasty is part of this process of creating new identity markers. However, whilst this does present a sort of legitimate return to the city's roots, a more important anchoring is also required. Like the temple, which followed the capital in its relocation, the commemorative park, a cultural site at the top of the hill, and the special day that is associated with it, are various factors that actively participate in the establishment of this new living space. Xin Yunyang's construction sites, such as the bridge, the parks and the many residences, will not merely serve to provide a modern and dynamic window to the world. They will also take part in the consolidation of the feeling of belonging to the place, by bringing about a sense of pride linked to the positive re-evaluation of the community. The process observed in Yunyang fits into a broader context, that of the creation of the municipality of Chongqing.

Recognition of the new municipality of Chongqing

On March 14th 1997, Chongqing became a municipality no longer subject to the authority of Sichuan province, but one directly dependent on the central government, in the same way as Peking, Shanghai and Tianjin. The Three Gorges project is one of the main reasons for this administrative promotion. Li Jianhong clearly explains the circumstances of this change in a region in which the residents, by and large, no longer consider themselves to be Sichuanese ${ }^{25}$. Chongqing will attempt to make the most of its new autonomy by trying to consolidate itself as an entity. In its quest for legitimacy and consolidation of identity, references to the past are going to play a vital role. The regional government's current initiatives, such as the new Culture Day or the creation of the Three Gorges Museum in Chongqing, are good examples of this. The Museum, 
which opened on June 18th 2005, will house more than three hundred thousand objects bearing witness to the history of the region and in particular to the Shu and Ba cultures as well as some original stellae from Zhang Fei's temple .

Within this regional process, Zhang Fei may yet again appear as a key element. Indeed, as legend has it, this general from "the former Sichuan" demanded that his head be buried in the territory of Shu, which he regarded as his real homeland. Opposition to the enemy land of $\mathrm{Wu}$ found in memoirs and legends seems still to exist today, particularly through the stigmatising of the residents of Hubei. Furthermore, the dam situated in this province, at the point of the former border between the territories of Shu and $\mathrm{Wu}$, is causing much more of an upheaval in Chongqing than in the economically better-off Hubei, which appears to be a clear beneficiary of it. Moreover, people there are experiencing much less trauma linked to the relocation, as the majority of the victims of the rising waters have the possibility of staying put.

Cultural and religious vestiges in the service of the promotion of the district

Cultural relics and the cult of Zhang Fei are put to use in a competition between the districts of the new municipality of Chongqing. The consequences of the administrative shake-up of the region and the change in the management of the territories inevitably bring about reformulations locally. Chongqing is seeking to consolidate its legitimacy as a particular entity, and its districts are also trying to establish their individual identities and distinguish themselves from each other. It is incumbent on Yunyang to legitimise its new status, all the more so in that the district has been elevated to the same administrative level as Wanzhou on which it previously depended. These various entities are in competition for the opening up of their territories, and are fighting as much with the weapons of tourism as through the creation of new markets. Thus, a strong and dynamic image of Yunyang as a culturally rich district will serve not only to attract tourists and unite its residents, but also to enable it to stand comparison with its neighbours.

The new capital, Xin Yunyang, is set to become the district's showcase, with its neat and tidy streets, its homes with modern comfort, its new buildings, its modern schools, its luxury hotels and its nicely laid out parks, all financed by a recent inflow of money from Peking. The building of the bridge and the relocation of the temple are benefiting from a strong advertising campaign. All these construction sites are promoting the region and showing Yunyang's capabilities and potential, but they are not the only ones to give an image of success and local prosperity. The area's deity will also be making its contribution. The transformations and renewed fame of the temple and of Zhang Fei himself, which have become emblems of wealth and modernity, will have repercussions for the district. Representing strength, might and combat, this hero is a revitalised positive symbol that will give new dynamism to the area. He is, together with the holy place devoted to him, a powerful lever enabling promotion of local success, all the more in that the temples dedicated to this deity are quite rare in China. The local pride that it brings clearly appears to be of a kind that can serve a political end. The inhabitants, like the members of the government, told me time and again in situ that the hero was "their Zhang Fei". They give the impression that this deity is venerated only in this district. And yet it is known as the god of boatmen from Chongqing to Wuhan ; statues and temples are dedicated to him in the neighbouring regions, and the accounts of his miracles are just as famous there. 
under the control of tourist companies or "requisitioned" with the sole aim of making a frenzied lunge for profit. They are not only regarded as places of consumption, as has been observed elsewhere in China ${ }^{26}$. It seems that through them the government is also taking an active part in the attempt at "rediscovery" of local history and in the reactivating of the memory of the inhabitants. The current political leaders, like the Chinese elites at other times in history, are using strategies of legitimation, but also of recomposition of the residents' identity, at the same time as reformulating community identity markers, which are being put to use through religion, among other things. It is all about restricting certain beliefs and stimulating others, showing, as in previous times, their ability to spread harmony and peace. To this end, they are promoting the local historical and cultural riches by encouraging a feeling of pride in and belonging to this new municipality, this shaken-up district and recomposed capital. It is this promotion of the regional culture of the past as well as the modern and dynamic image of the district that will enable it to stand competition with its neighbours and to motivate the residents made vulnerable by the recent traumas.

Some faithful and public servant use the politics of tourist development and the promotion of Chinese culture to have rituals recreated. The new Culture Day, the festivities reorganised by the government for Zhang Fei's birthday and the new parks mobilised a great number of inhabitants in Xin Yunyang. The reconstruction of the deity's home at the original place and the resumption of certain "traditional" activities forebode resistance by the residents to the attempts to modify and recompose their culture. Theses initiatives against the current of the government's politics can also be observed through the foundation of new small temples and altars in town as in the countryside.

\section{NOTES}

1. Concerning the dam over the Changjiang, cf. Dai Qing, The River Dragon Has Come, Armonk, N.Y., M.E. Sharpe, 1989. The writer has conducted a very active campaign against this project.

2. The local faithful call the pusa king Zhang.

3. Cf. the official biography of Zhang Fei in Chen Shou (233-297), Sanguozhi (History of the Three Kingdoms), Beijing, Zhonghua shuju, 1962, Zhangfei zhuan, volume 36.

4. Li Xiaoyun (ed.), Yunyang feng (The flirtations of Yunyang), Yunyang, 2003.

China Perspectives, 65 | may - june 2006 
5. The district of Yunyang lies two hundred kilometres from the Wu border, corresponding more or less to the present-day border with the province of Hubei. 6. In particular, two new rooms housing the bodhisattva Guanyin and the deity Caisheng have been opened.

7. Buddhists who have received an education but who do not have the status of monks are Sujiadizi.

8. Cf. Chongqing Statistical Yearbook 2004, Chongqing, Bureau of Statistics of the Municipality of Chongqing, 2004, p. 284, and Chongqing zongjiao (The religions of Chongqing), Chongqing, Chongqing chubanshe, 2000, pp. 423-424. No mention is made either of the temple or the worship of Zhang Fei in the description given of religion in Yunyang.

9. A number of structures have been set up there : a temple of the Emperor Gaozu, a commemorative portal dedicated to a virtuous local widow, as well as one of the gates taken from the former city of Yunyang. In the centre of the site, there is a display of a part of the famous series of stone engravings done by local and national artists since the Song. It was originally located at the foot of the temple of Zhang Fei.

10. Many legends reveal the importance of this offering in the religious practice, in particular that of the fisherman who for purposes of conservation had put the skull in a container of oil before burying it on the hillside.

11. A work by the local historian Hu Yaxing, Shudong mingzhu Yunyang (The Shimmering Pearl from the East of the Land of Shu : Yunyang), Chengdu, Sichuan daxue chubanshe, 1992, pp. 46-47.

12. Cf. Marianne Bujard, "Célébration et promotion des cultes locaux" (Celebration and Promotion of Local Cults), in Bulletin de l'Ecole Française d'Extrême Orient, Vol. I, No. 87, 2000, pp. 247-266.

13. That would correspond to a sort of "restoration" of the cult, a putting back in place of particular networks, as Brigitte Baptandier has shown through the example of another god "split up" between two villages in Fujian province. Cf. "Pratiques de la mémoire en Chine : le dieu des murs et des fossés de Puxi et Hanjiang" (Practices of Memory in China : the god of walls and ditches in Puxi and Hanjiang), in Genèses, 23, 1996 pp. 100-124.

14. Franciscus Verellen, "Shu as a hallowed land : Du guang ting's record of maërls", in Cahiers d'Extrême-Asie, 10, 1998, pp. 213-225.

15. The Ba lived in this region for two millennia before Christ, between the Xia and Shang dynasties, until the Zhou dynasty. In this connection, see Terry F. Kleeman, Great Perfection, Religion and Ethnicity in a Chinese Millennial Kingdom, Honolulu, University of Hawai'i Press, 1998. He explains in particular how the culture of the Tujia minority (present in the south of Yunyang) still has numerous Ba cultural traits.

16. The figures are much contested. Wei Yi, a Peking-based sociologist, puts at 120,000 the number of rural inhabitants forced to resettle in Yunyang, the most affected district. It has more than ten million residents according to the Chongqing Statistical Yearbook, op. cit.

17. See Florence Padovani, "Les effets sociopolitiques des migrations forcées en Chine liées aux grands travaux hydrauliques-l'exemple du barrage des Trois Gorges" (The Sociopolitical effects of forced migrations in China connected to the major hydraulic works-the example of the Three Gorges dam), Les Etudes du CERI, No. 103, April 2004. 18. Although they also represent a significant number of visitors. 
19. Like the Pavilion of Fair Winds, from the Song dynasty (960-1279), and the Du Fu Pavillon, from the Tang dynasty (618-907).

20. His qualities of loyalty and bravery also recall those that are regularly ascribed to the Ba people. Cf. Kleeman, op. cit., p. 44. Taking on such qualities amounts to a selfappropriation of proud and courageous forbears.

21. The temples that are said to have housed these relics were requisitioned at the time of the Cultural Revolution and turned into schools. The temple of Gaoyang was recently destroyed during the relocation of the city.

22. Cf. note 9.

23. According to the local government, the population of Lao Yunyang was put at 50,000 . Xin Yunyang, encompassing the residents of Lao Yunyang, Yun'an and Shuangjiang, today totals 110,000 people.

24. Yun'An is the former district capital, with a prestigious past.

25. Cf. Li Jianhong, "New Chongqing: Opportunities and Challenges", in John Fitzgerald (ed.), Rethinking China's Provinces, London, Routledge, 2002, pp. 41-87.

26. See the conference on the safeguarding of old Peking and the conflict between its modernisation and conservation, organised by the E.F.E.O. [Ecole Française d'ExtrêmeOrient/French Institute of the Far-East] and held in Peking on October 30th and 31st 2002 (Aurore Merle and Peng Youjun, "Peking Between Modernisation and Preservation”, China Perspectives, No. 45, January-February 2003, pp. 37-41).

\section{ABSTRACTS}

Yunyang, in the heart of the Three Gorges region, is bearing the brunt of the consequences of the dam's construction, through the flooding of agricultural lands, the resettlement of families, the wholesale rebuilding of urban centres and the relocation of the famous Zhang Fei temple. At the core of vital economic, ideological and symbolic interests are historical and religious relics and the worship of local deities. From local development policies to citizen initiatives, these fundamental markers of community identity are the subject of many different investments and reworkings. They are showing themselves to be particularly crucial for consolidation of the identity of the inhabitants frayed by the trauma that the region is currently undergoing. 